\title{
Cardiovascular events and atherogenic lipid profile in chronic myeloid leukemia patients treated with nilotinib versus imatinib
}

\author{
Petrikova $\mathrm{L}^{1,2}$, Slezakova $\mathrm{K}^{3}$, Sninska $\mathrm{Z}^{3}$, Harvanova $\mathrm{L}^{3}$, Martisova $\mathrm{M}^{3}$, Hatalova $\mathrm{A}^{3}$, Mistrik $\mathrm{M}^{3}$, \\ Batorova $\mathrm{A}^{3}$, Mladosievicova $\mathrm{B}^{1}$
}

Department of Clinical Pathophysiology, Institute of Pathological Physiology, Comenius University Faculty of Medicine, Bratislava, Slovakia. lucia.petrikova@nou.sk

\begin{abstract}
OBJECTIVES: The aim of this study was to assess cardiotoxicity and potential adverse effects related to lipid metabolism during treatment with tyrosine kinase inhibitors (TKIs) imatinib and nilotinib in patients with chronic myeloid leukemia (CML).

PATIENTS AND METHODS: Eighty-two consecutive patients with CML, who received nilotinib and/or imatinib in a single haemato-oncological Slovak center between years 2002-2018 were evaluated in a retrospective study. The mean age was 55.8 years (range 22-77 years). Median of follow-up was 61.3 months.

RESULTS: A significantly higher incidence of dyslipidemia, significantly higher levels of potential risk markers of cardiovascular disease small dense LDL cholesterol (sdLDL-CH) and a significant increase in total cholesterol were found in the patients during treatment with nilotinib in comparison to imatinib. Dyslipidemia led to drug therapy in $22 \%$ of the patients in the nilotinib group. Fourteen percent of the patients in the nilotinib group had one or more cardiovascular events, including peripheral artery disease (10\%), myocardial infarction (4\%) and stroke (4\%).

CONCLUSION: A higher risk of cardiovascular events and atherogenic dyslipidemia were associated with nilotinib therapy. Patients treated with TKI, especially nilotinib, require an early modification of cardiovascular risk factors and a careful cardiologic surveillance so that antileukemic therapy with this highly effective agent could continue (Tab. 4, Fig. 3, Ref. 32). Text in PDF www.elis.sk

KEY WORDS: tyrosine kinase inhibitors, cardiovascular events, dyslipidemia, small dense LDL-cholesterol, nilotinib, imatinib.
\end{abstract}

\section{Introduction}

The introduction of Bcr-Abl tyrosine kinase inhibitors (TKI), namely imatinib, dasatinib, nilotinib, bosutinib and ponatinib, in clinical practice has significantly improved the prognosis of chronic myeloid leukemia (CML) patients leading to the life expectancy comparable to the normal population (1). Despite successful results achieved with first-generation TKI imatinib, in nearly one-third of CML patients treatment must be discontinued, because of the intolerance or the resistance to therapy (2). Nilotinib, the second generation TKI was proven remarkably successful in chronic phase (CP)-CML with more rapid cytogenetic and molecular responses documented (3).

${ }^{1}$ Department of Clinical Pathophysiology, Institute of Pathological Physiology, Comenius University Faculty of Medicine, Bratislava, Slovakia, ${ }^{2}$ Department of Oncohematology, Faculty of Medicine Comenius University and National Cancer Institute, Bratislava, Slovakia, and ${ }^{3}$ Department of Hematology and Transfusiology, Faculty of Medicine, University Hospital Bratislava

Address for correspondence: L. Petrikova, MD, Institute of Pathological Physiology, Faculty of Medicine, Comenius University, Sasinkova 4, SK-811 08 Bratislava, Slovakia.

Phone: +421.259357272 , Fax: +421.259357601

Acknowledgements: This study was funded by VEGA 1/0610/18.
However, accumulating evidence suggests that nilotinib has the capacity to enhance the risk of cardiovascular events (CVEs), including coronary artery disease (CAD), ischemic cerebrovascular events and peripheral artery disease (PAD), especially in patients with cardiovascular $(\mathrm{CV})$ risk factors or concomitant cardiovascular disease (CVD) $(4,5,6)$. The incidence of CVEs induced by nilotinib has been reported with a wide range, from $0.5 \%$ to $35 \%$ of the patients affected (7). Some of these unfavorable effects continue even after the completion of the administration of TKIs. The molecular mechanism of vascular toxicity has not been definitively identified.

Based on new pathogenetic knowledge, vascular toxicity, i.e. cardiac damage, is classified as the type I (with irreversible structural damage to endothelium) and the type II (with transient endothelium dysfunction) (8). The Abelson (Abl) kinase is necessary for the viability of endothelial cells. The clinical presentation of vascular toxicity of Bcr-Abl inhibitors probably occurs due to vessel damage and progression of atherosclerotic process (9). Bcr-Abl inhibitors may also directly damage myocytes, which has been detected in animal models (10). Moreover, TKI inhibitor nilotinib was found to increase platelet adhesion ex vivo under flow and upregulate pro-atherogenic adhesion proteins on human endothelial cells, including ICAM1 (intercellular adhesion 
molecule 1), VCAM1 (vascular cell adhesion protein 1), plasma soluble P-and E-selectin and thereby contribute to the induction of a prothrombotic state (11).

The first-generation TKI imatinib seems to possess lipid lowering effects, on the contrary, therapy with nilotinib is associated with a negative effect on glucose and lipid metabolism, which may be another mechanism leading to accelerated atherosclerosis (12, 13). Major metabolic laboratory abnormalities may even occur early at the beginning of nilotinib treatment (2).

Not only hypercholesterolemia, but specifically the retention of low-density lipoprotein cholesterol (LDL-CH) and other cholesterol-rich apolipoprotein B (ApoB)-containing lipoproteins within the arterial wall is considered causal to atherosclerosis (14). Clinical trials documented that the lower the achieved LDL-CH, the smaller the risk of future CVEs, with no lower limit for LDL-CH values. The reduction of LDL-CH therefore is of prime concern in the prevention of the CVD (15).

Small dense LDL cholesterol (sdLDL-CH) is an emerging biomarker associated with CVD, considered to be the most atherogenic among the all seven LDL-CH subfractions (14). Triacylglycerol-rich lipoproteins, small dense LDL, and small dense HDL comprise the atherogenic lipid profile associated with an increased number of ApoB-containing particles (14). The sdLDL particles more effectively penetrate the arterial wall, showing a higher affinity for the intimal proteoglycans, with a more prolonged plasma half-life, a lower binding affinity for the LDL receptor, and a lower resistance to oxidative stress than large LDL (16). Patients with normal values of LDL-CH, but with an elevated representation of sdLDL particles may also be at a higher risk of CV disease development (17).

The aim of this study was to assess cardiovascular toxicity including PAD and potential adverse effects related to lipid metabolism with a focus on sdLDL-CH in CML patients treated with imatinib and nilotinib.

\section{Subjects and methods}

Eighty-two-CML patients in chronic phase, who received TKI nilotinib and/or imatinib in a single haemato-oncological Slovak center between the years 2002-2018 were evaluated in a retrospective study. All the patients (48 males and 34 females) were treated in the Department of Haematology at University Hospital Bratislava, specific laboratory measurements including sdLDL-CH were performed between October 2017 and August 2018. At the time of the examination, the average age of the patients was 55.8 years (range 22-77 years), the median of follow-up was 61.3 months (range 3.0-198.0 months). Patients were divided into two treatment groups: 32 patients received imatinib (IMA) and 50 patients received nilotinib (NILO).

The median duration of exposure to nilotinib was significantly shorter than to imatinib $51.6(3.0-123.6)$ months vs 126.2 (3.3$198.0)$ months $(\mathrm{p}<0.001)$. There were no significant differences in baseline characteristics and general risk factors between the IMA and NILO group before the initiation of TKIs. TKI for each patient was chosen individually. Nilotinib was given upfront in

\section{Tab. 1. CML variables and demographic data.}

\begin{tabular}{lc}
\hline Number of patients $(\mathrm{n}=82)$ & \\
\hline Age, years (mean \pm SD) & $55.82 \pm 13$ \\
\hline Gender $(\mathrm{n}, \%)$ & $48(58.5 \%)$ \\
$\quad$ Male & $34(41.4 \%)$ \\
$\quad$ Female & 61.35 \\
\hline Treatment duration (months) & $3.0-198.0$ \\
$\quad$ Median & \\
Range & $31(96.8 \%)$ \\
\hline Indication for TKI (n, \%): & $1(3.1 \%)$ \\
$\quad$ Imatinib & \\
$\quad$ First-line therapy & $31(62.0 \%)$ \\
$\quad$ Second-line therapy & $16(32.0 \%)$ \\
Nilotinib & $3(6.0 \%)$ \\
$\quad$ First-line therapy & $11(22.0 \%)$ \\
$\quad$ Second-line therapy & \\
Multiple TKIs ( $\geq 2)$ during study period & \\
\hline Reduced dose of nilotinib (n, \%) &
\end{tabular}

$31(62.0 \%)$ and after first-line imatinib in 16 patients (32.0\%). Three patients $(6.0 \%)$ received two TKIs (imatinib and dasatinib) before nilotinib treatment (Tab. 1).

Data on baseline parameters and CV risk factors, concomitant medication and medical history were obtained during clinical visits as well as from the patients' medical records. Medical history of atherosclerotic CVD and CV risk factors (age, sex, body mass index (BMI), waist circumference, smoking, arterial hypertension, diabetes mellitus (DM), dyslipidaemia were collected before and during TKI therapy. To rule out dyslipidaemia induced by other causes, we evaluated renal parameters and medical history or medication for hypothyreosis. The following CVEs were evaluated: CAD, PAD, ischemic cerebrovascular event, acute arterial occlusion.

The lipid profile was analysed during the therapy and compared to baseline values, the results of patients receiving lipid-lowering medication were not included in the analysis. Dyslipidaemia was defined as triacylglycerols $(\mathrm{TAG})>2.3 \mathrm{mmol} / \mathrm{l}, \mathrm{LDL} \geq 3.0 \mathrm{mmol} / \mathrm{l}$, $\mathrm{HDL}<1.2 \mathrm{mmol} / \mathrm{l}$ in women or $1.0 \mathrm{mmol} / \mathrm{l}$ in men or statin therapy (14). An additional optimal target of LDL values for high- risk CV patients ( $\mathrm{LDL}-\mathrm{CH} \geq 2.6 \mathrm{mmol} / \mathrm{l}$ ) was also evaluated.

Total cholesterol(TCH), LDL-CH, HDL-cholesterol(HDL-CH), and TAG were measured enzymatically using an automatic analyser (Elecsys analyser, Roche Diagnostics) and commercial assay kits. Blood samples were taken after 12-hour fasting in the morning collected for the measurement of sdLDL-CH, which were measured by a homogeneous assay method (sdLDL-EX "Seiken", Denka Seiken, Tokyo, Japan). Based on the information provided by the manufacturer (Denka Seiken) for the evaluation of CV risk, a cut-off of $0.9 \mathrm{mmol} / 1$ was determined (18). Atherogenic index of plasma (AIP) was defined as the logarithm of TAG to HDL-CH ratio (19). Using AIP calculator, the patients were categorized into 3 groups - low, intermediate, and high risk (20). BMI and waist circumference were accepted as similarly strong in detection of obesity (14). Body mass index (BMI) $\geq 30 \mathrm{~kg} / \mathrm{m}^{2}$ and waist above $\geq 94 \mathrm{~cm}$ for men or $\geq 80 \mathrm{~cm}$ for women was defined as increased (adapted for European population). Total CV risk was evaluated ac- 


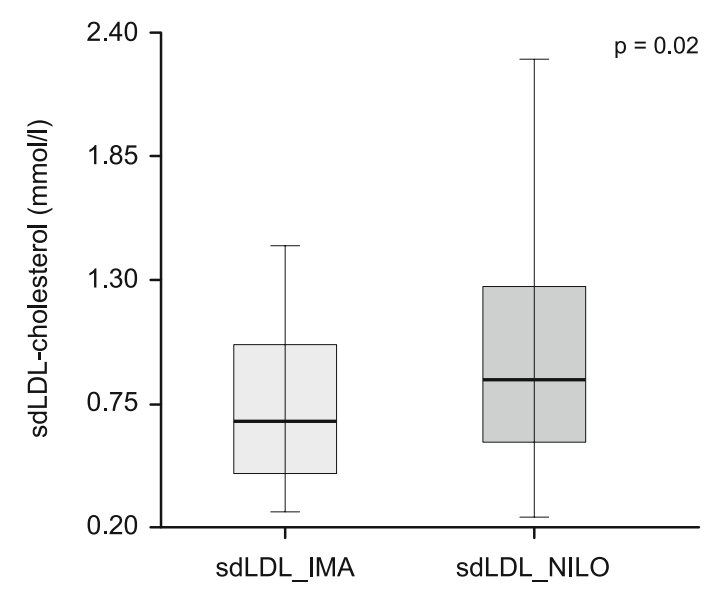

Fig. 1. SdLDL-cholesterol values in imatinib and nilotinib patients $(\mathrm{p}=\mathbf{0 . 0 2})$.

cording the 2016 European Society of Cardiology (ESC) guidelines on cardiovascular disease prevention in clinical practice. SCORE (Systematic Coronary Risk Estimation) calculator adapted for high-risk regions (http://www.HeartScore.org) was used to assess the 10-year risk of CVD at baseline and throughout therapy (15).

Patients with a documented atherosclerotic CVD, including acute coronary syndrome (ACS), stable angina, coronary revascularization, stroke and transient ischemic attack (TIA), PAD or DM with target organ damage or SCORE $\geq 10 \%$ were defined as patients with a very high-risk CVD risk. Patients with marked hypercholesterolemia $(>8 \mathrm{mmol} / \mathrm{l})$, LDL-CH $>4.9 \mathrm{mmol} / \mathrm{l}$ or marked hypertension $(\mathrm{BP} \geq 180 / 110 \mathrm{mmHg}$ ), patients with familiar hypercholesterolemia (FH), DM without target organ damage, SCORE $>5 \%$ and $<10 \%$ were defined as patients with a high CVD risk (15). According SCORE, patients were classified to low- (SCORE $<1 \%$ ), moderate- $(\geq 1 \%$ and $<5 \%$ ), high- $(\geq 5 \%$ and $<10 \%$ ) and very high-risk (SCORE $\geq 10 \%$ ) groups.

Tab. 2. Characteristics of patients during TKI therapy $(n=82)$.

\begin{tabular}{|c|c|c|c|}
\hline & Imatinib $(\mathrm{n}=32)$ & Nilotinib $(n=50)$ & $\mathrm{p}$ \\
\hline Age years (mean \pm SD) & $56.57(14.17)$ & $55.31(12.70)$ & 0.6670 \\
\hline $\begin{array}{l}\text { Treatment duration } \\
\text { (median, min-max) }\end{array}$ & $126.25(3.33-198.00)$ & $51.65(3.00-123.60)$ & 0.0000 \\
\hline Dyslipidemia overall & $14(43.75 \%$ & $41(82.00 \%)$ & 0.0067 \\
\hline Dyslipidemia new & $5(15.62 \%)$ & $21(42.00 \%)$ & 0.0152 \\
\hline $\begin{array}{l}\text { Total cholesterol during TKI, mmol/L } \\
\text { (mean } \pm \text { SD) }\end{array}$ & $4.57(1.00)$ & $5.38(1.05)$ & 0.0027 \\
\hline $\begin{array}{l}\text { LDL-CH during TKI, mmol/L } \\
(\text { mean } \pm \mathrm{SD})\end{array}$ & $3.14(0.85)$ & $3.79(1.03)$ & 0.0110 \\
\hline $\begin{array}{l}\text { sdLDL-CH during TKI, mmol/L } \\
(\text { mean } \pm \text { SD) }\end{array}$ & $\begin{array}{l}0.73(0.41) \\
(\mathrm{n}=23)\end{array}$ & $\begin{array}{l}0.99(0.51) \\
(\mathrm{n}=38)\end{array}$ & 0.0200 \\
\hline $\begin{array}{l}\text { HDL-CH during TKI, mmol/L } \\
(\text { mean } \pm \mathrm{SD})\end{array}$ & $1.39(0.39)$ & $1.59(0.42)$ & 0.0260 \\
\hline $\begin{array}{l}\text { Triacylglycerols during TKI, mmol/1 } \\
(\text { mean } \pm \text { SD) }\end{array}$ & $1.40(0.68)$ & $1.91(0.99)$ & 0.5961 \\
\hline
\end{tabular}

This study was approved by the Ethics Committee of University Hospital Bratislava, all the patients provided a written consent.

\section{Statistical analysis}

Categorical variables are presented as the counts and percentages. Continuous variables are presented as the mean \pm standard deviation (SD) and/or median and range. ANOVA, Mann-Whitney U test or Kruskal-Wallis test were used for the comparisons between continuous variables. Differences between categorical data were assessed using the chi-square test. Repeated measures ANOVA was used for comparing the samples before and during therapy. Cumulative incidence method was used to calculate cumulative incidence of dyslipidaemia. The log-rank test was used to compare two or more groups of stratified patients. $\mathrm{p}<0.05$ (twosided) was considered statistically significant. All the statistical analyses were undertaken using NCSS v.10.

\section{Results}

\section{Lipid profile and sdLDL-cholesterol}

During the therapy with TKIs, dyslipidaemia was observed more frequently in the patients treated with nilotinib. The newly diagnosed dyslipidaemia was present in 5/32 (15.6\%) patients in the IMA group and in $21 / 50(42.0 \%)$ patients in the NILO group $(\mathrm{p}=0.0152)$. Overall, $43.7 \%$ patients in the IMA group and $82.0 \%$ patients in the NILO group had non-optimal lipid values $(\mathrm{p}=0.0067)$.

In the NILO group, we found higher levels of sdLDL-CH, when compared to patients exposed to imatinib (IMA vs NILO: $0.73 \pm 0.41 \mathrm{mmol} / 1$ vs $0.99 \pm 0.51 \mathrm{mmol} / 1 ; \mathrm{p}=0.02$ ) (Fig. 1 ). Atherogenic lipid profile with predominance of sdLDL-CH $(\geq 0.9 \mathrm{mmol} / \mathrm{l})$ was present in $7 / 23(30.4 \%)$ patients in the IMA group and in $17 / 38(44.7 \%)$ patients in the NILO group ( $p=0.29)$.

The mean concentrations of TCH and LDL-CH differed significantly across the study groups, data are shown in Table 2. Patients receiving nilotinib had a higher mean HDL-CH concentration (IMA vs NILO 1.39 $\pm 0.39 \mathrm{mmol} / 1 \mathrm{vs} 1.59 \pm 0.42 \mathrm{mmol} / 1$, respectively; $\mathrm{p}=0.026)$. Elevated TAG levels $(>2.3 \mathrm{mmol} / \mathrm{l})$ were detected in $6 / 29$ $(20.6 \%)$ patients in the IMA group and in $10 / 38(26.3 \%)$ patients in the NILO group, which was similar in both groups $(p=1.0000)$.

During therapy with nilotinib, TCH had risen by the mean of $1.11 \mathrm{mmol} / \mathrm{l}$ with the mean plasma TCH concentration of 5.39 mmol/1 (SD: 0.13) (Fig. 2, Tab. 3). There was a statistically significant difference in $\mathrm{TCH}$ levels before and on-treatment $(p=0.0000)$. Consequently, among NILO patients without cholesterol-lowering medication $72.9 \%(27 / 37)$ patients had increased LDL-CH values and in $18.9 \%$ patients we observed levels $\geq 4.9 \mathrm{mmol} / \mathrm{l}$ associated 


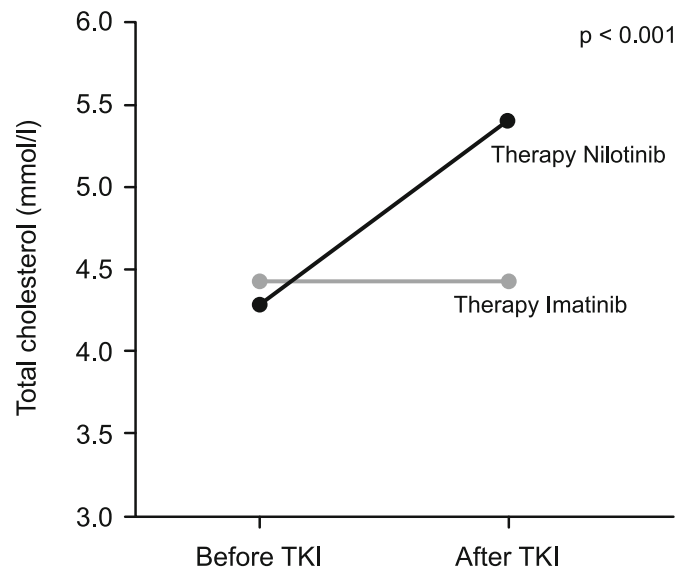

Fig. 2. The mean total cholesterol concentration baseline and during therapy.

with high CV risk according to the ESC guidelines. The rise in LDL-CH during TKI treatment resulted in the prescription of lipidlowering drugs in patients, which were newly indicated in $2 / 32$ $(6.2 \%)$ patients in the IMA group vs $11 / 50(22.0 \%)$ patients in the NILO group $(\mathrm{p}=0.0687)$.

Regarding AIP, there were no differences in percentage of high- risk patients between the groups (IMA vs NILO $24.0 \%$ vs $22.2 \%, \mathrm{p}=1.000$ ). Cumulative incidence of dyslipidaemia during follow-up was $22.2 \%(95 \% \mathrm{CI} 0.08-0.60$, month 175$)$ in the IMA group vs $62.3 \%$ (95\%CI $0.46-0.83$ at month 100$)$ in the NILO group, log-rank test ( $\mathrm{p}=0.0022)$ (Fig. 3).

\section{Cardiovascular risk factors}

Newly diagnosed obesity was present in 5/29 (17.2 \%) patients in the IMA group vs $14 / 49(28.5 \%)$ in the NILO group ( $\mathrm{p}=$ 0.2907). In the NILO group, we detected a statistically significant increase in BMI during therapy from $26.85 \pm 0.28 \mathrm{~kg} / \mathrm{m}^{2}$ to $28.40 \pm$ $0.28 \mathrm{~kg} / \mathrm{m}^{2}(\mathrm{p}=0.0004)$. Systolic blood pressure also increased by the mean of $9.8 \mathrm{mmHg}$ (baseline $125.9 \pm 2.3 \mathrm{mmHg}$, after therapy $135.78 \pm 2.3 \mathrm{mmHg}, \mathrm{p}=0.0043)$.

Tab. 3. Changes in total cholesterol and CV risk factors during TKI therapy.

\begin{tabular}{|c|c|c|c|c|}
\hline & Imatinib & $\mathrm{p}$ & Nilotinib & $\mathrm{p}$ \\
\hline $\begin{array}{l}\text { Baseline total cholesterol } \\
\text { Total cholesterol during TKI } \\
(\mathrm{mmol} / \mathrm{l})\end{array}$ & $\begin{array}{l}4.41(0.22) \\
4.42(0.22) \\
(\mathrm{n}=14)\end{array}$ & 0.9784 & $\begin{array}{l}4.28(0.13) \\
5.39(0.13) \\
(\mathrm{n}=29)\end{array}$ & 0.0000 \\
\hline $\begin{array}{l}\text { Baseline BMI } \\
\text { BMI during TKI }\left(\mathrm{kg} / \mathrm{m}^{2}\right)\end{array}$ & $\begin{array}{c}26.60(0.48) \\
28.09(0.48) \\
(\mathrm{n}=12) \\
\end{array}$ & 0.0522 & $\begin{array}{l}26.85(0.28) \\
28.40(0.28) \\
\quad(n=46) \\
\end{array}$ & 0.0004 \\
\hline $\begin{array}{l}\text { Baseline Syst. BP } \\
\text { Syst. BP during TKI } \\
(\mathrm{mmHg})\end{array}$ & $\begin{array}{c}132.62(2.44) \\
135.81(2.44) \\
\quad(n=16)\end{array}$ & 0.3717 & $\begin{array}{c}125.97(2.30) \\
135.78(2.30) \\
\quad(n=47)\end{array}$ & 0.0043 \\
\hline $\begin{array}{l}\text { SCORE before TKI } \\
\text { SCORE during TKI ( } \%)\end{array}$ & $\begin{array}{l}4.43(0.53) \\
6.56(0.53) \\
(n=16)\end{array}$ & 0.0127 & $\begin{array}{l}3.46(0.34) \\
6.58(0.34) \\
(n=43)\end{array}$ & 0.0000 \\
\hline
\end{tabular}

Continuous variables summarized as mean $( \pm$ SD), Syst. BP - systolic blood pressure, SCORE - systematic coronary risk estimation calculator, TKI - tyrosine kinase inhibitor

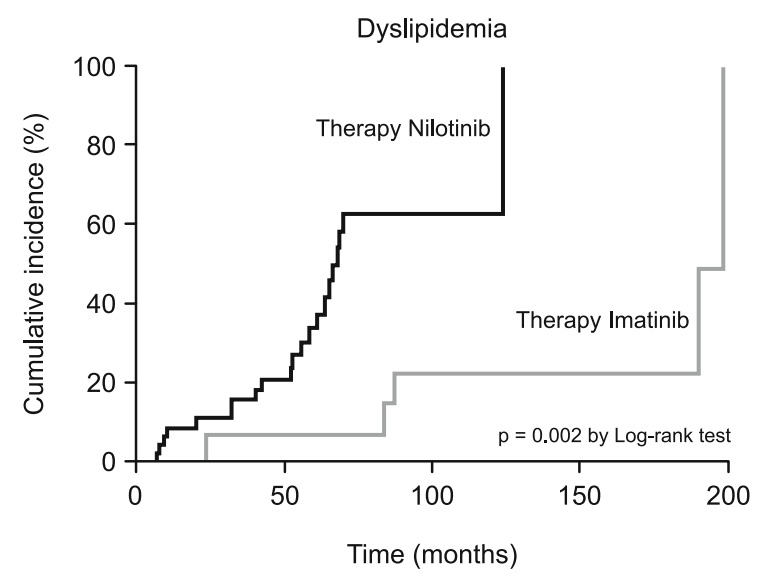

Fig. 3. Cumulative incidence of dyslipidemia.

We observed an increase in the 10-year risk of fatal CVD during NILO and IMA treatment. In the IMA group, SCORE increased from $4.43 \pm 0.53 \%$ to $6.56 \pm 0.53 \%(\mathrm{p}=0.0127)$ and in the patients exposed to NILO from $3.46 \pm 0.34 \%$ to $6.58 \pm 0.34 \%$ $(\mathrm{p}=0.0000)$. In the NILO group, $12 / 44$ patients $(27.2 \%)$ patients with a previous low $\mathrm{CV}$ risk moved to a high/very high-risk category vs $3 / 16(18.7 \%)$ patients in the IMA group. The analysis of total CV risk showed that $6 / 32(18.7 \%)$ patients in the IMA group and $18 / 50(36 \%)$ in the NILO group $(p=0.13)$ had a very high risk of future CVE.

\section{Cardiovascular events}

During the follow-up, no cardiovascular death occurred, however, seven patients $(14.0 \%)$ in the NILO group experienced one or more CVEs. The most frequent manifestation was PAD, detected in 5 patients $(10.0 \%)$. In four patients $(8.0 \%)$ PAD was newly developed, in one patient deterioration of pre-existing PAD was found. The median time to occurrence of PAD was 58.3 (32.2112.7) months after the start of NILO treatment with the average age of $66.4( \pm 3.88)$ years.

In two patients in the NILO group (4\%) non-ST elevation myocardial infarction (NSTEMI) with the need of vascular intervention was observed and two patients $(4.00 \%)$ experienced cerebrovascular event. The median time to occurrence for NSTEMI was 41.4 (32.2-50.7) months, for stroke 86.1 (59.5-112.7) months. All the patients had multiple CV risk factors. The individual clinical characteristics of the patients with CVEs are listed in Table 4.

\section{Discussion}

According to our knowledge, the present study is the first one to analyse sdLDL-CH in CML patients treated with TKIs. We eva- 
Tab. 4. Individual characteristics and CV risk factors of patients with documented cardiovascular events treated with nilotinib.

\begin{tabular}{|c|c|c|c|c|c|c|c|c|}
\hline \multicolumn{2}{|c|}{$\begin{array}{c}\text { Patient number } \\
\text { and gender }\end{array}$} & \multirow{2}{*}{$\begin{array}{c}\begin{array}{c}\text { Age at } \\
\text { CVE (years) }\end{array} \\
69.3 \\
\end{array}$} & \multirow{2}{*}{$\begin{array}{c}\text { Time to occurrence } \\
\text { (months) }\end{array}$} & \multirow{2}{*}{$\begin{array}{c}\begin{array}{c}\text { NILO dose } \\
(\mathrm{mg})^{\mathrm{a}}\end{array} \\
600\end{array}$} & \multirow{2}{*}{$\begin{array}{l}\text { Risk factors present } \\
\text { at CVE } \\
\text { HTN, DLP, IFG, ECS }\end{array}$} & \multirow{2}{*}{$\frac{\text { Statin }^{\mathrm{b}}}{\text { yes }}$} & \multirow{2}{*}{$\begin{array}{c}\text { SCORE } \\
\text { very high }\end{array}$} & \multirow{2}{*}{$\frac{\text { CVEs }}{\text { PAD-deterioration }}$} \\
\hline 1 & $\mathrm{M}$ & & & & & & & \\
\hline 2 & $\mathrm{M}$ & 64.3 & 32.3 & 600 & HTN, IFG, DLP, obesity, ECS & no & very high & PAD \\
\hline 3 & $\mathrm{~F}$ & 59.8 & 112.7 & 800 & HTN, IFG, smoker, ECS & no & high & Stroke, PAD \\
\hline 4 & $\mathrm{M}$ & 70.3 & 63.6 & 800 & HTN, T2DM, obesity & no & high & PAD \\
\hline 5 & $\mathrm{~F}$ & 61.5 & 59.5 & 800 & HTN, obesity & no & moderate & Stroke \\
\hline 7 & M & 68.3 & 50.7 & 800 & HTN, T2DM, DLP, obesity & yes & high & $\begin{array}{c}\text { CAD-NSTEMI } \\
\text { (CABG) }\end{array}$ \\
\hline
\end{tabular}

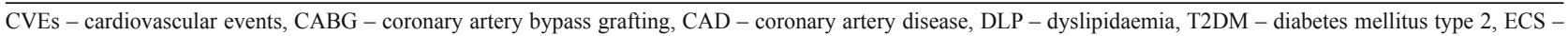
ex-cigarette smoker, F - female, HTN - arterial hypertension, IFG - impaired fasting glucose, LDL-CH - low-density lipoprotein, NSTEMI - non-ST-segment elevation myocardial infarction, $\mathrm{M}$ - male, $\mathrm{MI}$ - myocardial infarction, $\mathrm{PAD}$ - peripheral artery disease, $\mathrm{PCI}$ - percutaneous coronary intervention, SCORE - systematic coronary risk estimation calculator, TKI - tyrosine kinase inhibitor, ${ }^{\mathrm{a}}$ nilotinib dose before CVE, ${ }^{\mathrm{b}}$ statin use before CVE

luated a cohort of $82 \mathrm{CML}$ patients, who received nilotinib and/or imatinib with the median follow-up of 61.3 months. In the NILO group we found 1) significantly higher levels of potential risk marker of CAD sdLDL-CH, 2) significantly higher incidence of dyslipidaemia, 3) significant increase in total cholesterol during treatment 4) increase in CV risk and the occurrence of CVEs including PAD, myocardial infarction and stroke.

In the present study, patients in the NILO group had significantly higher levels of sdLDL-CH. Sd-LDL-CH have been increasingly studied as a better marker for CVD outcomes.

A positive association between sdLDL-CH levels and CAD was recently documented in the study by Liou et al. In this metaanalysis, data from 21 studies with a total 30628 patients were collated. Authors confirmed that the presence of sdLDL-CH was associated with an increased risk of developing CAD and this association was independent of conventional CV risk factors, as well as consistent across different measurement methods. Their results support sdLDL-CH as a risk marker of CAD and suggest sdLDL-CH as a potential therapeutic marker for CAD risk reduction (21).

In the study we found a high prevalence of dyslipidaemia, which was more frequent in the NILO group, although patients treated with nilotinib were followed for a shorter period. Newly developed dyslipidaemia was found in more than one third of patients with a previously normal lipid profile. Patients in the NILO group had a higher cumulative incidence of dyslipidaemia, increased levels of TCH, LDL-CH and HDL-CH and they were more frequently indicated to lipid-lowering medication compared to the IMA group.

Our results are in agreement with the authors Rea et al., who documented the effect of nilotinib on lipid profile in a single-centre, prospective study with $27 \mathrm{CML}$ patients. Nilotinib significantly increased TCH, LDL-CH, HDL-CH within three months after the start of the therapy. As the result, in the NILO group, the proportion of patients with elevated LDL-CH increased nearly twofold by 12 months (2). In the prospective study by Hornak et al. with 57 de novo CP-CML patients treated with nilotinib or imatinib for 9 and 12 months, respectively, they reported a significant increase in TCH, LDL-CH and HDL-CH concentration 6 months after the beginning of the nilotinib therapy (22).
Consistent with our findings, abnormalities of TCH, LDL-CH, HDL-CH in patients exposed to nilotinib were documented by other authors $(23,24)$. In contrast to cholesterol, TAG concentrations seemed to decrease during treatment with nilotinib $(2,22$, 25). A trend towards to a decrease in TAG was present in our data, although it did not reach a statistical significance.

Cardiovascular comorbidities are frequent in the patients with CML (26). Combined cumulative effect of hypertension and high LDL-CH was associated with the increase in the risk of CVEs by 37 times (13). We observed that established CV risk factors such as: elevated blood pressure and BMI worsened during nilotinib therapy. Nearly one third of the patients in the NILO group had a very high risk of future CVE, however, the change in SCORE $\mathrm{CV}$ risk towards higher values was present in both of the groups. A lower prevalence of patients with a high $\mathrm{CV}$ risk than in our study was reported by Hornak et al, presumably due to differences in age and baseline comorbidities of the patients in the NILO group (22).

In the prospective study by Caocci et al in 369 CML adult patients with the median age 50 years and median follow-up 4 years, who were stratified according to the SCORE system, the patients with $\mathrm{TCH}>5.17 \mathrm{mmol} / \mathrm{l}$ and LDL-CH $>1.8 \mathrm{mmol} / \mathrm{l} 3$ months after treatment had a significantly higher incidence of CVEs and high or very high SCORE risk maintained a significant association with CVEs (25). The authors concluded that SCORE risk seemed to be useful to predict the development of atherosclerotic events in CML patients treated with nilotinib and should be calculated before the start of any TKIs (27).

There has already been some evidence published suggesting that new TKIs could be associated with CVEs, with reported 5-year risk of cardiovascular ischemic events two times higher with nilotinib than with imatinib (28). However, most studies have focused on CAD only. To address this gap, we were focusing also on peripheral artery disease (PAD). In our study, $14 \%$ of the patients in the NILO group experienced one or more CVEs and PAD was the most frequent CVE. Our results are consistent with the study by Caocci et al. These authors demonstrated that PAD was frequent CVE in patients after a long-term exposure to nilotinib (25). 
$531-537$

Also, retrospective analysis of the incidence of nilotinib-associated CVEs in 220 patients with CML at 17 Australian institutions showed that with median follow-up of 42 months, CVEs occurred in $12 \%$ of the patients with an incidence of 4.1 events per 100 patient-years of exposure. CAD was the most common, followed by PAD and ischemic cerebrovascular events. Age and dyslipidaemia were identified as independent variables for their development. Importantly, authors observed a high rate of recurrence of CVEs in patients continuing nilotinib after the first event in spite of standard management measurements and $21 \%$ patients stopped nilotinib because of adverse events (7).

The discrepancy between the study of Hornak et al. with no CVEs observed during their follow-up and the presented study might be explained by a shorter follow-up of patients in the nilotinib group in their study, patients were also younger and had less baseline comorbidities compared to imatinib group (22).

Interestingly, the majority of the patients in our study, who experienced CVEs, received higher doses of nilotinib. Regarding nilotinib, the risk of CVEs seems to be dose related, which was suggested by the results of the meta-analysis that included 4659 participants from 14 trials. Second-generation TKIs increased the risk of CVEs compared to imatinib and the difference was significant for nilotinib. CVEs occurred more frequently with nilotinib $800 \mathrm{mg}$ than with nilotinib $600 \mathrm{mg}$. Authors concluded that of 1000 CP-CML patients, 38 more patients will develop a CVE with second-generation TKIs compared to imatinib (29).

Recently published 10-year follow up data from randomized phase 3 trial ENESTnd with 546 patients showed that the risk of $\mathrm{CAD}$, ischemic cerebrovascular events and PAD was higher in individuals treated with nilotinib in a dose dependent fashion. Higher cumulative rates of CVEs were reported with nilotinib (600 mg, vs $800 \mathrm{mg}$ ) than with imatinib, CVE rates were $10.6 \%, 17.9 \%$, and $3.2 \%$, respectively, at 5 years and continued to increase to $24.8 \%, 33.4 \%$, and $6.3 \%$, respectively, at 10 years (30).

The lipid abnormalities that we detected in nilotinib-treated patients are established atherosclerotic CVD risk factors in nonCML population. According to the recent ESC guidelines, total CV risk should guide the intensity of intervention. Individuals with a high or very high CV risk do not need the use of a risk SCORE and require an immediate attention to risk factors. High-risk persons with calculated SCORE $5 \%$ and $<10 \%$ may be candidates for drug treatment, in very-high-risk persons with SCORE $\geq 10 \%$, modification of risk factors and adequate therapy is necessary (14).

In CML patients treated with TKIs, modification of all CV risk factors including hypertension, dyslipidaemia, hyperglycaemia is advised. Currently, CV risk assessment prior to the initiation of therapy with nilotinib and monitoring of risk at one, three and six-month follow up visits is recommended (31). The measurement of Ankle brachial index and Doppler ultrasound of lower extremity arteries at baseline and every 6 or 12 months has been recently recommended in patients treated with nilotinib (32). Discontinuation of nilotinib and switch to another TKI may be considered in situations, where the risk of the drug may outweigh the benefit, such as the onset of a severe adverse event like arterial occlusion.

\section{Limitation of the study}

One of the limitations of our study is a small size of the study groups associated with a lower prevalence of CML in population. Not all the patients received nilotinib as the first-line treatment, although the percentage of patients, who were treated with nilotinib upfront was quite high (62\%). On the other hand, the followup period of the patients was considerably long, with the median of follow-up 61.3 months, additionally there were no significant baseline differences in age, characteristics and general CV risk factors between imatinib and nilotinib group.

\section{Conclusion}

With a longer survival of CML patients, an increased focus is targeted on cardiovascular toxicity of TKIs. Our findings indicate that patients with CP-CML should be screened for lipid disorders and $\mathrm{CV}$ risk factors prior to and during TKI therapy. SdLDL-cholesterol as a new risk marker of CAD might be a useful tool for identification of CML patients at risk of developing CVEs. The thorough monitoring of CV complications, as well as an early elimination of their risk factors are necessary to prevent the occurrence of CVEs including PAD so that therapy with these effective agents could continue.

\section{References}

1. Varga A, Tilea I, Petra DN, Tilinca MC, Gliga ML, Demian S. Cardiovascular events throughout the disease course in chronic myeloid leukaemia patients treated with tyrosine kinase inhibitors - a single centre retrospective study. J Clin Med 2020; 9 (10): 3269.

2. Rea D, Mirault T, Cluzeau T, Gautier JF, Guilhot F, Dombret H, Messas E. Early onset hypercholesterolemia induced by the 2nd-generation tyrosine kinase inhibitor nilotinib in patients with chronic phase-chronic myeloid leukemia. Haematologica 2014; 99 (7): 1197-1203.

3. Berdeja JG, Heinrich MC, Dakhil SR, Goldberg SL, Wadleigh M, Kuriakose $\mathrm{P}$ et al. Rates of deep molecular response by digital and conventional PCR with frontline nilotinib in newly diagnosed chronic myeloid leukemia: a landmark analysis. Leuk. Lymphoma 2019; 60 (10): 2384-2393.

4. Damrongwatanasuk R, Fradley MG. Cardiovascular Complications of Targeted Therapies for Chronic Myeloid Leukemia. Curr Treat Options Cardiovasc Med 2017; 19: 24.

5. Haguet H, Douxfils J, Mullier F, Chatelain C, Graux C, Dogne JM. Risk of arterial and venous occlusive events in chronic myeloid leukemia patients treated with new generation BCR-ABL tyrosine kinase inhibitors: A systematic review and meta-analysis. Expert Opin Drug Saf 2017; 16 (1): $5-12$.

6. Jain P, Kantarjian H, Boddu PC, Nogueras-Gonzales GM, Verstovsek S, Garcia-Manero G et al. Analysis of cardiovascular and arteriothrombotic adverse events in chronic-phase CML patients after frontline TKIs. Blood advances 2019; 3 (6): 851-861.

7. Minson AG, Cummins K, Fox L, Costello B, Yeung D, Cleary R et al. The natural history of vascular and other complications in patients treated with nilotinib for chronic myeloid leukemia. Blood advances 2019; 3 (7): 1084-1091.

8. Hermann J. Tyrosine Kinase Inhibitors and Vascular Toxicity: Impetus for a Classification System? Curr Oncol Rep 2016; 18 (6): 33. 
9. Mladosievicova B, Petrikova L, Valaskova Z, Bernadic JrM, Chovanec $\mathbf{M}$, Mego $\mathbf{M}$ et al. Atheroclerosis in cancer patients. Bratisl Med J 2019; 120 (9): 636-640.

10. Hasinoff BB, Patel D, Wu X. The Myocyte-Damaging Effects of the BCR-ABL1-Targeted Tyrosine Kinase Inhibitors Increase with Potency and Decrease with Specificity. Cardiovasc Toxicol 2017; 17 (3): 297-306.

11. Alhawiti N, Burbury KL, Kwa FA, O’Malley CJ, Shuttleworth P, Alzard $\mathbf{M}$ et al. The tyrosine kinase inhibitor, nilotinib potentiates a prothrombotic state. Thromb Res 2016; 145: 54-64.

12. Gacic J, Vorkapic E, Olsen RS, Söderberg D, Gustafsson, Geffers R, T et al. Imatinib reduces cholesterol uptake and matrix metalloproteinaise activity in human THP-1 macrophages. Pharmacol Rep 2016; 68 (1): 1-6.

13. Aghel N, Lipton JH, Atenafu EG, Kim DDH, Delgado DH et al. Cardiovascular event after exposure to nilotinib in chronic myeloid leukemia: long- term follow-up. Clin Lymphoma Myeloma Leuk 2017; 17 (12): 870-878.

14. Mach F, Baigent C, Catapano AL, Koskinas KC, Casula M, Badimon L et al. 2019 ESC/EAS Guidelines for the management of dyslipidaemias: lipid modification to reduce cardiovascular risk: The Task Force for the management of dyslipidaemias of the European Society of Cardiology (ESC) and European Atherosclerosis Society (EAS). Eur Heart J 2020; 41 (1): 111-188.

15. Piepoli MF, Hoes AW, Agewall S, Albus CH, Brotons C, Catapano AL et al. 2016 European Guidelines on cardiovascular disease prevention in clinical practice: the sixth joint task force of the european society of cardiology and other societies on cardiovascular disease prevention in clinical practice (constituted by representatives of 10 societies and by invited experts) developed with the special contribution of the European Association for Cardiovascular Prevention \& Rehabilitation (EACPR). Eur Heart J 2016; 37 (29): 2315-2381.

16. Hoogeveen RC, Gaubatz JW, Sun W, Dodge RC, Crosby JR, Jiang J et al. Small dense low-density lipoprotein cholesterol concentrations predict risk for coronary heart disease: the atherosclerosis risk in communities (ARIC) study. Arterioscler Thromb Vasc Biol 2014; 34 (5): 1069-1077.

17. Malhotra J, Tonorezos ES, Rozenberg M, Vega GL, Sklar CA, Chou J et al. Atherogenic low density lipoprotein phenotype in long-term survivors of childhood acute lymphoblastic leukemia. J Lipid Res 2012; 53 (12): 2747-2754.

18. https://www.sks.sk/system/files/referencie_biochemia.pdf

19. Abolnezhadian F, Hosseini SA, Alipour M, Zakerkish M, Cheraghian B, Ghandil Pet al. Association Metabolic Obesity Phenotypes with Cardiometabolic Index, Atherogenic Index of Plasma and Novel Anthropometric Indices: A Link of FTO-rs9939609 Polymorphism. Vasc Health Risk Manag 2020; 16: 249.

\section{0. http://www.biomed.cas.cz/fgu/aip/calculator.php}

21. Liou L, Kaptoge S. Association of small, dense LDL-cholesterol concentration and lipoprotein particle characteristics with coronary heart disease: A systematic review and meta-analysis. PloS one 2020; 15 (11): e0241993.
22. Hornak T, Semerad L, Zackova D, Weinbergerova L, Sustkova Z, Prochazkova J et al. Analysis of serum lipids, cardiovascular risk, and indication for statin use during nilotinib and imatinib therapy in de novo CML patients - results from real-life prospective study. Leuk Lymphoma 2020; 61 (2): 494-496.

23. Iurlo A, Orsi E, Cattaneo D, Resi V, Bucelli C, Orofino N et al. Effects of first- and second-generation tyrosine kinase inhibitor therapy on glucose and lipid metabolismin chronic myeloid leukemia patients: a real clinical problem? Oncotarget 2015; 6: 33944-33951.

24. Franklin M, Burns L, Perez S, Yerragolam D, Makenbaeva D. Incidence of type 2 diabetes mellitus and hyperlipidemia in patients prescribed dasatinib or nilotinib as first-or second-line therapy for chronic myelogenous leukemia in the US. Curr Med Res Opin 2018; 34 (2): 353-360.

25. Caocci G, Mulas O, Capodanno I, Bonifacio M, Annunziata M, Galimberti, S et al. Low-density lipoprotein (LDL) levels and risk of arterial occlusive events in chronic myeloid leukemia patients treated with nilotinib. Ann Hematol 2021; 1-10.

26. Jabbour EJ, You M, Le TK, Brokars J, Brun A, Makenbaeva D et al. Prevalence of comorbidities relevant to the choice of second-generation (2-G) tyrosine kinase inhibitor (TKI) for the treatment of chronic myeloid leukemia (CML) in the United States using real-world claims databases. Blood 2018; 132 (Suppl 1): 4265-4265.

27. Caocci G, Mulas O, Annunziata M, Luciano L, Bonifacio M, Orlandi EM et al. Cardiovascular toxicity in patients with chronic myeloid leu-kemia treated with second-generation tyrosine kinase inhibitors in the real-life practice: identification of risk factors and the role of prophylaxis. Am J Hematol 2018; 93 (7): E159-E161.

28. Hochhaus A, Saglio G, Hughes TP, Larson RA, Kim DW, Issaragrisil S et al. Long-term benefits and risks of frontline nilotinib vs imatinib for chronic myeloid leukemia in chronic phase: 5-year update of the randomized ENESTnd trial. Leukemia 2016; 30 (5): 1044-1054.

29. Haguet H, Graux C, Mullier F, Dogné JM, Douxfils J. Long-Term Survival, Vascular Occlusive Events and Efficacy Biomarkers of FirstLine Treatment of CML: A Meta-Analysis. Cancers 2020; 12 (5): 1242.

30. Kantarjian HM, Hughes TP, Larson RA, Kim DW, Issaragrisil $\mathrm{S}$, le Coutre $\mathbf{P}$ et al. Long-term outcomes with frontline nilotinib versus imatinib in newly diagnosed chronic myeloid leukemia in chronic phase: ENESTnd 10-year analysis. Leukemia 2021: 1-14.

31. Manouchehri A, Kanu E, Mauro MJ, Aday AW, Lindner JR, Moslehi, J. Tyrosine kinase inhibitors in leukemia and cardiovascular events: from mechanism to patient care. Arterioscler Thromb Vasc Biol 2020; 40 (2): 301-308.

32. Alexandre J, Cautela J, Ederhy S, Damaj GL, Salem JE, Barlesi, F et al. Cardiovascular toxicity related to cancer treatment: a pragmatic approach to the American and European cardio-oncology guidelines. J Am Heart Assoc 2020; 9 (18): e018403.

Received February 16, 2021. Accepted March 3, 2021. 